\title{
Toward an Automatic Reduction of Non-added Values Tasks in the Project-Product-Process Domain
}

\author{
Jeremy Boxberger ${ }^{1}$, Mathieu Lebouteiller ${ }^{2}$, Toufik Boudouh ${ }^{3}$, and Samuel Gomes ${ }^{3}$ \\ ${ }^{1}$ Zurfluh-Feller, 45 Grande Rue, 25150 Autechaux-Roide \\ ${ }^{2}$ Faurecia, Bois sur Près, 25550 Bavans \\ ${ }^{3}$ Laboratoire M3M, UTBM, 90010 Belfort Cedex
}

\begin{abstract}
To increase their competitiveness, companies need to increase the turnover of their products. They should continuously develop attractive new products efficiently in order to increase sales volume and ensure sustainability in globalized markets. The streamlining of routine engineering processes becomes necessary to improve quality and productivity in design and allows more time to develop innovative products. The main goal of our contribution is to develop a design process framework to allow a reduction in routine design processes which will thus increase time available for innovative design processes. The methodology proposed consists of integrating data management, information management, knowledge management, and decision-support methods and tools, such as PDM (product data management), PLM (product lifecycle management), and KBE (Knowledge based engineering). In the area of knowledge management, some methodologies exist to reduce non-added value tasks such as KBE models, Top down design or Design for X (Design for manufacture, Design for assembly, dis-assembly, etc...). Our methodology deals with the reduction of routine design by automatic design project initiation, including knowledge management. This methodology is tested in a firm specialized in rolling shutter components. This approach allows time reduction of "non-added value tasks" and allows justifying any specification by knowledge and know-how gained in the past. When a new design project is created, often it will require one or several manufacturing processes to create the product. So, the designer has to use his own skills and experience to define the task lengths. One issue is how to keep the information usable by every designer, not only the expert. Another issue is how to preserve the knowledge embedded into the product, the manufacturing process and also in the project. Our contribution uses automatic project initiation, stored in a PLM tool. The automatic generation is based on several models which use configuration containing parameters and knowledge. By introducing a tool using this methodology in an industrial firm, we can reduce routine design and improve design robustness. Additional research will be performed towards an ergonomic use of the tool.
\end{abstract}

Keywords: Lean engineering, Iteration, Product life management, workflow. 


\section{Introduction}

In a more competitive economic environment, to sustain their business, companies must adapt and change their engineering processes to improve design performance and increase their three main indicators: quality cost and delivery. In order to introduce our work, we will discuss some methods of business organization, then we will see the importance of using software such as Product Data Management (PDM) or Product Lifecycle Management (PLM), then explanations about wasting time and iteration will be introduced. In addition, management planning and resources will now be collaborative in a product-process-project approach. To test the concepts proposed we use a tool for collaborative design within the scope of PLM applied to a small engineering firm. Today, organization varies from company to company because of the size, the sector of activity, the maturity, or the history of the company [1]. Considering now the data management project-product-process throughout the life cycle, the PDM evolves toward PLM [2], which corresponds to a real business strategy for creating and maintaining the product definition throughout its life cycle, through to the establishment of the product offer until the end of life. Excellent communication between stakeholders of different services of the company fosters the development of concurrent engineering. Unlike engineering, where work is carried out sequentially, concurrent engineering has several advantages. It allows the overlapping of tasks, which in turn allows gains in terms of time and quality. It also improves communication within the project team. This global vision of development emerged in the late 80's under different names such as integrated engineering [3] [4] simultaneous [5], distributed [6], concurrent [7] [8] (concurrent engineering), or collaborative [9] [10]. Moreover, continual improvement is conducted in the design models using lean engineering concepts [11]. This consists, just like lean manufacturing, in searching for matching and deleting non value -added tasks. Project creation often creates wasted time, which contains non added value and iterations: Iteration of design tasks is an intrinsic characteristic of the design process. Indeed, design cannot be performed in a single long process. Concurrent engineering is a product development method where iterations occur more significantly between tasks. Tasks are achieved in parallel or overlapped resulting in more interactions, therefore in more iteration. Iterations are needed to improve design quality, to support creativity, and to explore new solutions. Iterations are also often necessary for rework imposed by downstream tasks in the design process. Hence, certain iterations should be planned in order to arrive at a satisfactory design solution, and other iterations are unplanned and stem from either a bad scheduling of design tasks or from design errors. In the perspective of lean engineering, inefficient iterations are considered as waste. In this case, the iterative process is a non-added value activity in the design process and should be minimized. [12] [13]. The objective of our contribution is to integrate within a type of PLM architecture, project management including resource management, resource availability, loading rate, hourly cost of resources and manufacturing processes knowledge in order to have a homogeneous distribution between all the projects with realistic workloads. Our goal is to test these features of traditional project management instead of workflow tools commonly used in PLMPDM [14] [15] systems while automating the project management tool and reducing routine tasks which allow time saving for the users. [16] 


\section{Methodology}

Routine design takes up a huge amount of time in industry. This routine design contains iteration loops: we make a calculation or attempt several times to find the best parameters, the best planning, etc. Our method deals specifically with routine iteration reduction in projects. Checking team users' workloads, checking their availability, etc. is wasted time during project schedule building. Wasted time in the design phase stage is well known now and certain applications are used to reduce routine product design, such as KBE application. But wasted time is also present in the project domain of the design process. The use of a tool for scheduling management and document sharing, coupled with a streamlined design methodology can reduce this wasted time by simplifying the implementation of a project, document archiving, and can improve communication between key contributors (actors). ACSP is an organizational tool developed by the University of Technology of BelfortMontbéliard for collaborative project management with these features. This tool also provides a software environment for distributed collaborative design [2], centralizing various data relating to the proposed design of the "product", the "process" and "activities" associated with them. The difference of the tool can be represented in the table below (Table 1) where a cross means that the option is present.

Table 1. Review of available functions in various type of project information management tools

\begin{tabular}{lccc}
\hline \multicolumn{1}{c}{ FunctionalitylTool } & ACSP & PLM Tool & WBS Tool \\
\hline View management & & $\mathrm{X}$ & \\
Workflow management & & $\mathrm{X}$ & \\
Configuration management & $\mathrm{X}$ & $\mathrm{X}$ & \\
Functional analysis of product & $\mathrm{X}$ & & \\
Functional analysis of process & $\mathrm{X}$ & & \\
Specifications management & $\mathrm{X}$ & $\mathrm{x}$ & \\
Bill of materials management & $\mathrm{X}$ & & \\
Knowledge management (parameters & & & \\
and rules) & $\mathrm{X}$ & & $\mathrm{X}$ \\
Automatic KBE application builder & $\mathrm{X}$ & $\mathrm{X}$ & \\
Access right management & $\mathrm{X}$ & $\mathrm{X}$ & \\
Roles management & $\mathrm{X}$ & $\mathrm{X}$ & \\
Communication / forum & $\mathrm{X}$ & $\mathrm{x}$ (Wind-chill) & \\
Planning management & $\mathrm{X}$ & & $\mathrm{X}$ \\
Project Template management & $\mathrm{X}$ & & \\
Resources management & $\mathrm{X}$ & $\mathrm{X}$ & $\mathrm{X}$ \\
Workload Management & $\mathrm{X}$ & & \\
Financial aspect management & & & \\
\hline
\end{tabular}

Positioned in the context of concurrent engineering [7], the objective of such a tool is to support the design process in terms of cooperation between key contributors such as design process engineers, technicians, directors, users, operators, manufacturing and so on. The insertion of a special project creation module allows project building 
tasks such as planning, teamwork and individual workloads, the manufacturing process and the knowledge process to be reduced. The SADT diagrams (Figure 1) illustrate the method baseline.

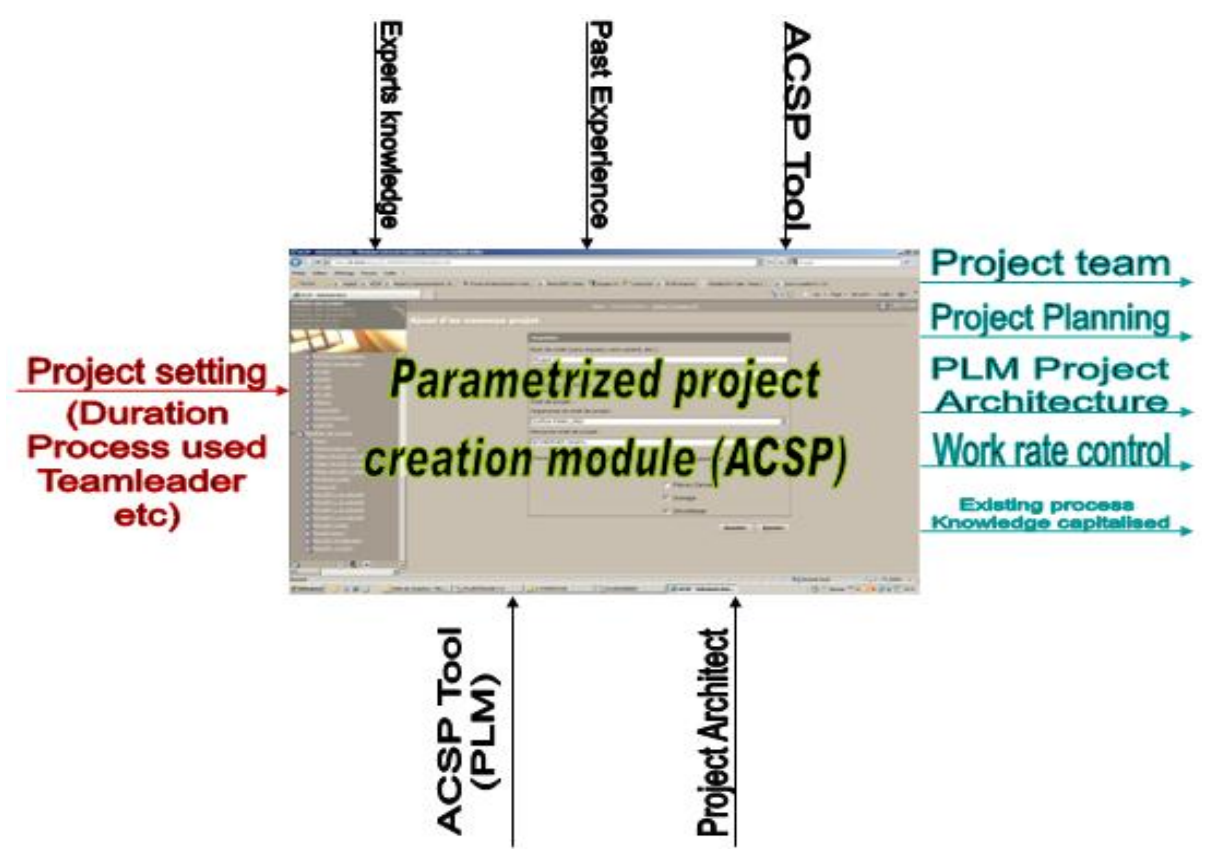

Fig. 1. ACSP automatic project creation

The method of creation is composed of several steps. The first is to choose the kind of project (short or long), then the processes involved in the project. As a result, the key people are inserted accordingly into the process. At the end the team project is chosen. This step is the responsibility of the PLM Architect. The next step is the responsibilities of the team leader who can add people and adjust, if necessary, the planning which has been automatically created. He can also check the work load of his team and adjust accordingly. The ultimate goal is to simplify the communication and exchange of documents within the firm. In addition to its goals of sharing and exchange of data inherent in the design, ACSP also aims to generate project summary documents used in the capitalization of project data: functional specifications, developer specifications, product file, and so on. Meanwhile, the ACSP provides scheduling information, facilitating their research. It also allows a better definition of a project (planning, define project team, workloads, etc.), and better visualization of tasks to be performed by each [17] [18]. It is necessary in a project that the actors work together and communicate for a strong cohesion of the work, and a homogeneous and realistic distribution of tasks. In addition to the basic document management function of the PLM, the tool must manage the interchanging of the tasks. Standardization of some project templates, with predefined tasks (according to the different manufacturing processes included in the project), standard task duration, 
standard documents and intelligent connections between the tasks, allow time to be saved during development of the project plan. The workloads visualization of each actor within the project also allows the construction of a realistic forecast plan, taking into account other projects. Thus, the semi-automatic project, built from standard projects, allows the creation of a new project, including project management, without the use of the traditional tools of workflow.

\section{Use Case}

In this part we explain how we have reduced the time wasted in non value-added actions in the following sub-parts: The first part is the creation of a new project. The software allows the user to select the type of project he wants to create according to the manufacturing process which is included in the project. The different manufacturing processes are plastic injection, sheet metal forming, powder sintering, machining and stamping. The user selects the manufacturing processes which can be used during the project, and also the length of the project. By using standard project models, the project is created using appropriate task lengths, according to the processes selected. In addition, the process expert is automatically inserted in the project, and the team leader can check his availability, to avoid overloads. Furthermore, each manufacturing process includes knowledge which is automatically inserted in the project as product process design specifications. This methodology was tested in a small firm specialized in manufacturing shutter part components. This company did not have a standard design method established. We were able to identify several barriers to the integration of the PLM tool in such an environment. The main difficulty was the resistance to change of the employees [19], but also the number of ongoing projects and the amount of data to be added by each actor in the project. As an actor in the implementation of such a tool, it seemed necessary to present a clear and usable tool. The first task carried out in relation to setting up the ACSP tool was to list all the deliverables and tasks integrated in a project in the state. Indeed, the company had no standard design procedure for these projects and project activities were performed in any order, with the result that information could be lost and communication was not efficient. Once the tasks were identified, the next step was to define standards of deliverables, according to a model that can be shared by all actors. A standard scheduling of these tasks was needed to standardize and streamline project information. A BPMN diagram was constructed using Gantt chart laws in order to organize these tasks. Business Process Model and Notation (BPMN) is a graphical representation for specifying business processes in a business process model [20]. Additional research to find the standard average duration of these tasks was achieved with the help of expert people using their knowledge and experience. This phase has revealed that the length of a project depends mainly on the number of manufacturing processes used in the project. Two different project templates were created: short and long. A long project is often an innovative project, where functional analysis, benchmarking, targeting or intellectual property analysis are included. A short project contains fewer tasks. The difference with a long project is that it is characterized by a more controlled environment which is much better known; the phase of information research is much shorter and simpler. Figure 2 shows the differences between both models by highlighting the design phase. In a short project, team work reflecting on the 
choice of a way to high or low risk is determined in advance by experts and leaders. In case of high risks, a feasibility study is carried out including a product and process FMEA. If the project runs low risk (for example, the customer wants an additional mounting hole), a solution is selected by cost quality and delay analysis based on experience and know-how during a collective brainstorming.

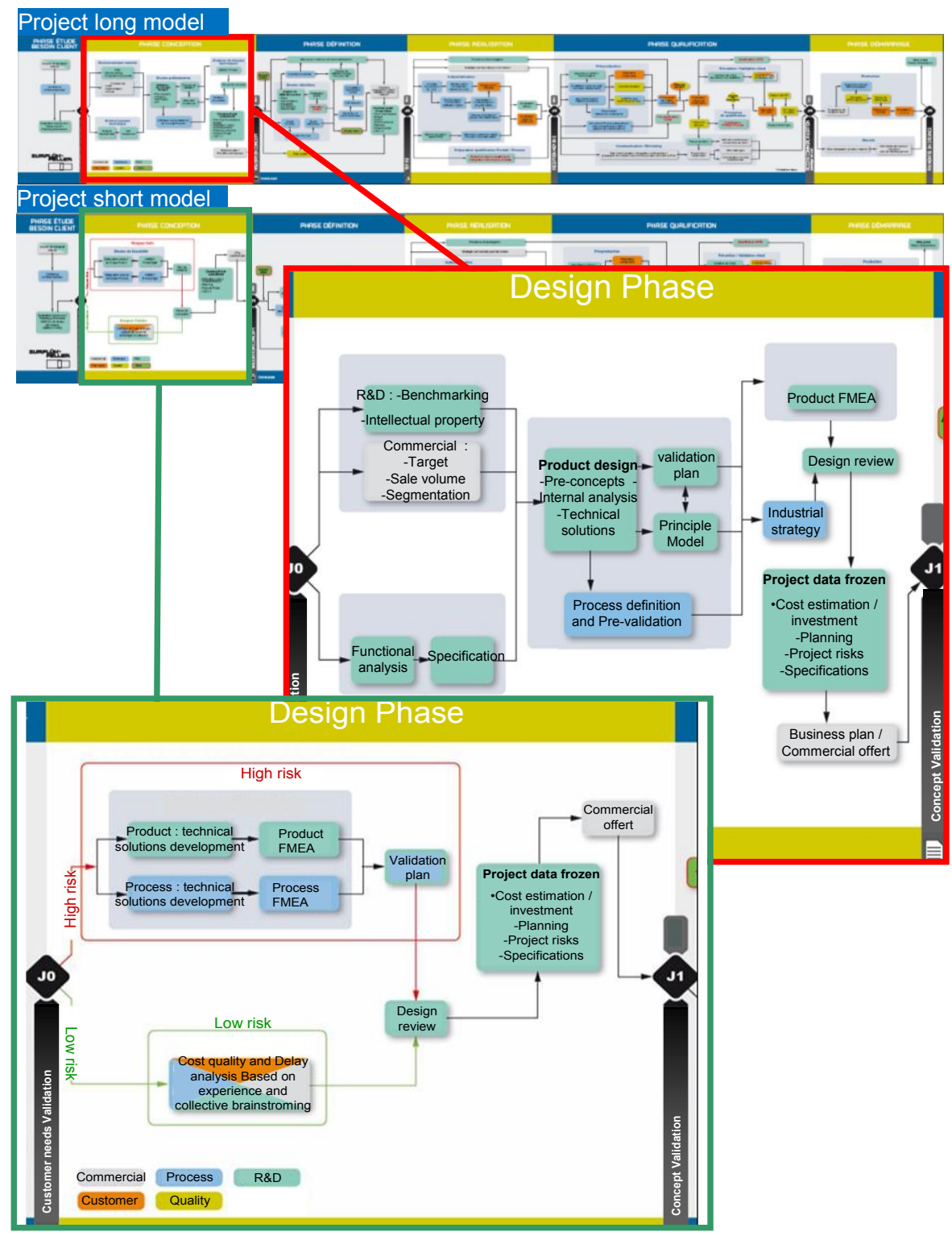

Fig. 2. Standard project models 
The capitalization of this experiment is therefore necessary to facilitate and accelerate quantification of future projects. In general, projects consist of modifications of existing components, or creating a product variant on the basis of a well-known model. These routine tasks mainly occupy $60 \%$ of company projects studied. Thus, in a short project, the commercial offer for the customer is arrived at much more quickly than in a long project. Responsiveness is the most important factor for the customer.

\subsection{Experimental Protocol Implemented for the Analysis of Ongoing Projects}

The tool ACSP is instrumented in order to quantify the changes in different types of projects. Indeed, performance indicators, based on respect of original deadlines have been established for each project. Other performance indicators are expected to provide a qualitative analysis of the design process, for example, through the documents most frequently traded by the designers, the task more frequently opened, the number of non-validations of a task (waste) etc... This work will then improve the proposed models (Figure 3), highlighting the tasks that are sometimes omitted or never used. In addition, the deliverables will bring more efficiency to current and future designs. Performance indicators will confirm whether the segmentation of tasks is appropriate. Using this analysis, we can also identify the critical paths, and provide more accurate duration of the standard steps of the model. We will improve the reliability of planning and can distribute the workload more evenly between stakeholders. Other analysis tools will highlight the process step where delays are recurring, and target, identify and implement an action plan to avoid them in the future.

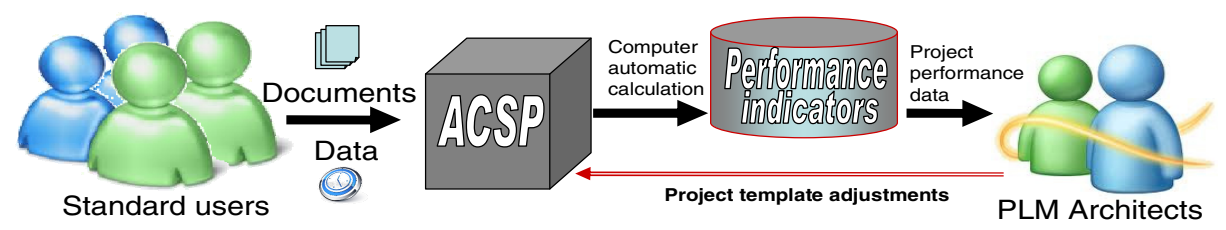

Fig. 3. Project template continual improvement

\subsection{Automating the Projects Creation}

The module allows automatic creation of a project more quickly and easily than a traditional method (Figure 4). Based on performance indicators to capitalize the experience of the company, project templates (long and short) are continuously optimized. When a new project is created, the system updates the standard tasks duration according to the project length (ratio from project template) and updates the actual workload and the standards document. This allows an automatic upstream overview of the entire project, thereby improving the timeliness, quality, and organization of the project, but also a better level of customer response in terms of costs and lead time. In addition, using the intelligent project duplication module, projects of different lengths can be created from the standard project through 
automated coefficients, and setting: length, manufacturing processes, team leader and type of project. Thus, the user avoids performing an update on the duration of each task of a new project. In addition, according to the process chosen in the project (plastic injection, sheet metal forming, machining, stamping, etc.), knowledge and how-know, which can be formalised, are automatically included in the project as variables. Then, these variables could be used by the project actors or the process experts. For example, the variables included in the plastic injection process are the ranges of settings for the molding machine, or the relevant rules of plastic parts. These variables can be extracted in a KBE application and 3D design tree.

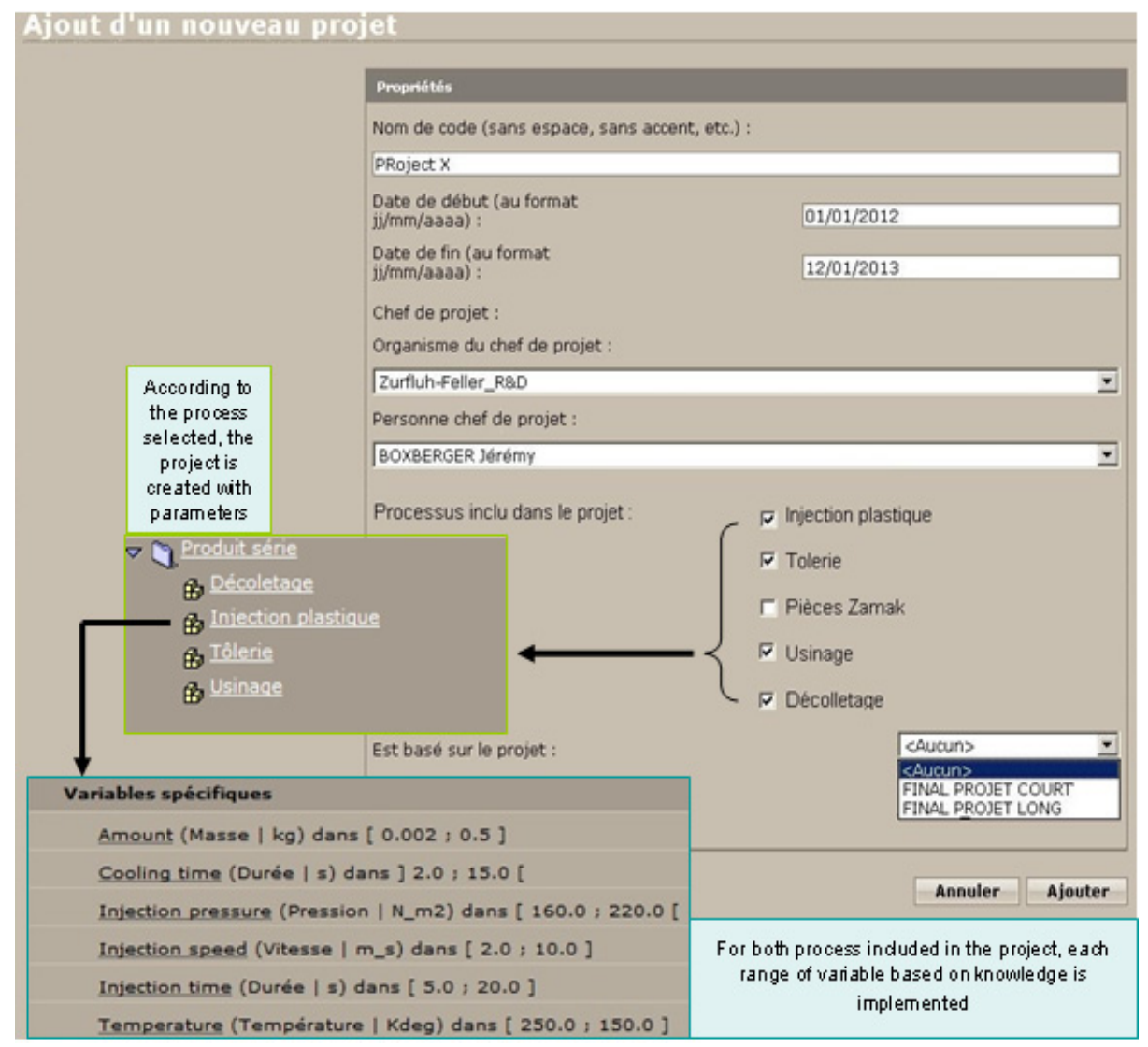

Fig. 4. New parameterized project creation

\section{Conclusion}

The addition to project management in semi-automated manufacturing PLM generates significant time savings in setting up a new project. Resource management and automatic verification workloads can create projects with realistic deadlines and alleviate work overload of team members. In parallel, the performance indicators 
enable continuous improvement of standard project templates. After the introduction of the tool ACSP in the company and its use by all business stakeholders, the prospects for highly productive engineering can be deployed specifically in terms of product and process. Thus, having capitalized knowledge of the company and by coupling ACSP / KBE (Knowledge based engineering) [16], it becomes possible to automatically generate applications such as "Kadviser" (four-dimensional parametric model incorporating the business rules of previously capitalized products). The aim is always to reduce the time dedicated to routine tasks.

\section{References}

[1] Bressy, G., Konkuyt, C.: Management Et éConomie Des Entreprises. Sirey (2008)

[2] Gomes, S., Monticolo, D., Hilaire, V., Mahdjoub, M.: A Multi-Agent System Embedded to a PLM to Synthesize and Re-Use Industrial Knowledge. International Journal of Product Lifecycle Management 2(4), 317-336 (2007)

[3] Andreasen, M., Hein, L.: Integrated Product Development. IFS, Springer (1985)

[4] Tichkiewitch, S., Chapa, E., Belloy, P.: Un Modèle Produit Multi-Vues Pour La Conception Intégrée. In: Productivity In World Without Borders Conference, Montréal (1995)

[5] Bocquet, J.-C.: Ingénierie Simultanée, Conception Intégrée, Conception De Produits Mécaniques: Méthodes, Modèles Et Outils, Sous La Direction De M. Tollenaere. Hermès, pp. 29-52 (1998)

[6] Brissaud, D., Garro, O.: An Approach to Concurrent Engineering Using Distributed Design Methodology. Concurrent Engineering: Research and Applications 4(3), 303-311 (1996)

[7] Sohlenius, G.: Concurrent Engineering. Annals of the CIRP 41(2), 645-655 (1992)

[8] Prasad, B.: Concurrent Engineering Fundamentals. PTR Prentice Hall, Upper Saddle River (1996); vol I: Integrated Product and Process Organization (ISBN 0-13-147463-4) and Vol II: Integrated Product Development (ISBN 0-13-396946-0)

[9] Li, W.D., Lu, W.F., Fuh, J.Y.H., Wong, Y.S.: Collaborative Computer-Aided Design Research and Development Status. Computer-Aided Design 37, 931-940 (2005)

[10] Lu, S.C.-Y., Elmaraghy, W., Schuh, G., Wilhelm, R.: A Scientific Foundation of Collaborative Engineering. CIRP Annals - Manufacturing Technology 56(2), 605-634 (2007)

[11] Wang, X., Conboy, K., Cawley, O.: "Leagile" Software Development: An Experience Report Analysis of the Application of Lean Approaches in Agile Software Development. Journal of Systems and Software 85(6), 1287-1299 (2012)

[12] Steward, D.V.: The Design Structure System: A Method for Managing the Design of Complex Systems. IEEE Transactions on Engineering Management EM-28(3), 71-74 (1981)

[13] Browning, T.: Applying The Design Structure Matrix to System Decomposition and Integration Problems: A Review and New Directions. IEEE Trans. Eng. Manage 48, 71$74(2001)$

[14] Chvidchenko, I., Chevalier, J.: Conduite \& Gestion De Projets (1994)

[15] Levan Serge, K.: Le Projet Workflow, Concept Et Outil Au Service Des Organisations (2000) 
[16] Cantamessa, M., Montagna, F., Neirotti, P.: An Empirical Analysis of the PLM Implementation Effects in the Aerospace Industry Original Research Article. Computers in Industry 63(3), 243-251 (2012)

[17] Gomes, S., Sagot, J.C.: A Concurrent Engineering Experience Based on a Cooperative and Object Oriented Design Methodology. Best Papers Book From 3rd International Conference on Integrated Design and Manufacturing in Mechanical Engineering, pp. 11-18. Kluwer Publishers, Dordrecht (2002)

[18] Gomes, S., Serrafero, P., Monticolo, D., Eynard, B.: Extracting Engineering Knowledge from PLM Systems: An Experimental Approach. In: International Conference In Product Lifecycle Management, Lyon, pp. 33-43 (2005)

[19] Balogun, J.: Veronica Hope Hailey Exploring Strategic Change, 2nd edn. Financial Time/Prentice Hall (2004)

[20] Ko, R.K.L., Lee, S.S.G., Lee, E.W.: Business Process Management (BPM) Standards: A Survey. Business Process Management Journal 15(5) (2009) 